\title{
SELECTING A PROFOUND TECHNICAL SERVICE PROVIDER TO PERFORM A TECHNICAL FIELD DEVELOPMENT STUDY FROM GIVEN MULTIPLE CRITERIA
}

\author{
Slamet Riyadi ${ }^{*}$, Lokman Effendi and Rafikul Islam \\ Department of Business Administration, International Islamic University Malaysia P.O. Box 10, \\ 50728 Kuala Lumpur, Malaysia
}

\begin{abstract}
The analytic hierarchy process (AHP) method has been used to identify the best technical service provider to perform a field development plan (FDP) document of Field X. AHP is the method that can be used to solve multi-criteria decision making (MCDM) problem. AHP structures a MCDM problem by developing a decision hierarchy which presents the relationships of goal, criteria and alternatives. The Technology Capability and the Project Deliverability criteria show the highest overall weight; those are 0.270 and 0.244 respectively, while Reliability Company and Technology Transfer have similar lowest numbers of the overall weight; those are 0.067 and 0.069 respectively. The Cost criterion is the third highest, and the Track Record Performance criterion is the fourth highest, that is 0.188 and 0.162 respectively. The Provider 5 and Provider 1 have the highest and the second highest of the overall weight; those are 0.2895 and 0.2546 respectively, while the Provider 2 has the lowest overall weight; that is 0.1246 . That means, based on this method, the Provider 5 is selected as the provider to conduct the works of developing FDP for the Field X.
\end{abstract}

Keywords: Analytical hierarchy process (AHP); goal; criteria; alternative, field development plan (FDP).

\section{Introduction}

Oil price is at high level and it seems will continue to be high in the next following years. There was showing increasing exponentially the oil price from early 2005 to the present years. Although the last few years the world economic indicates slowing down and continuing to mid of 2010. Oil price has been indicating around $\$ 100$ per barrel in the last several months. If we expect the economic recovery would be in place for the next coming years, with this premise, we expect the oil price would be on the range of $\$ 90$ to 110 per barrel $^{1}$.

On the other hand, the production performance as the source of generating revenue to the company in most of the major fields is declining. Routine optimization could not be able to stop the production decline. After the peak production in around 1996 the production continues to decline till the current date. If there is no a major study to assess comprehensively the potential of the field, the production will continue to decline. With these consequences, the abandonment of the Field X could be predicted in the short coming period. This means that the reserve replacement to the Company will not be achieved. This means that the performance of the Company overall will be declined ${ }^{3}$.

The question is how to resolve the problem. A comprehensive study to evaluate the Field $\mathrm{X}$ is must. The potential of the field is there. The current recovery is about $34 \%{ }^{3}$. This means that there is still potential to recover more. All the optimization works with the primary method have been conducted. The next step is the assessment should go beyond the primary recovery. Meaning that the works need involvement all major disciplines from Geologist, Geophysicist, Petro physicist, Geo Modeller, Reservoir Simulation Engineer with EOR background, Production Technologist, Drilling Engineer, Completion Engineer, Facility Engineer, and Project Economist. The next question is how to gather these resources, is there any in house expertise available to do the works with commitment time frame?

\footnotetext{
${ }^{*}$ Corresponding author
} 
From the current assessment of the corporate level, the staff level to conduct the existing works is even still a gap. Some recruitment processes have been conducted but the suitable candidate showed unpromising. This means that Team who is responsible for Field $\mathrm{X}$ has to outsource the works to a technical service provider.

In summary, due to the following reasons: oil price is relative stable at high price and continue to stay or rise in the next followings years, production performance indicates declining, the Field $\mathrm{X}$ still has potential to be recovered more, limited resources to conduct in house study, and at the current situation the Government is asking to boost the production as high as possible to fill the gap, therefore the Team has to prepare a document to conduct a bidding to look for a qualified technical service provider.

\section{Methodology}

\subsection{Analytic Hierarchy Process (AHP) Method}

The approach of selecting the technical service providers is by using the Analytic Hierarchy Process (AHP) method. This method is a multi-criteria decision making tool. AHP is the method that can be used to solve multi-criteria decision making (MCDM) problem. This method has been applied is many other areas, such as accounting, conflict analysis, energy, finance, health, marketing, portfolio management, R \& D management, risk analysis, technology, many other areas ${ }^{2}$.

AHP structures a MCDM problem by developing a decision hierarchy which presents the relationships of goal, criteria, sub-criteria (if it is required), and alternatives. The following are steps to proceed the selecting the technical service provider: Define the goal or objective, define the criteria of to select a technical provider, identify alternatives, develop questionnaires, conduct survey, analyze the results, and derive a conclusion.

Figure 1 shows a general structure of the decision hierarchy involving four major criteria and five alternatives. The each criterion 1 and 2 has two sub-criteria, while criterion 3 and 4 does not have sub-criteria.

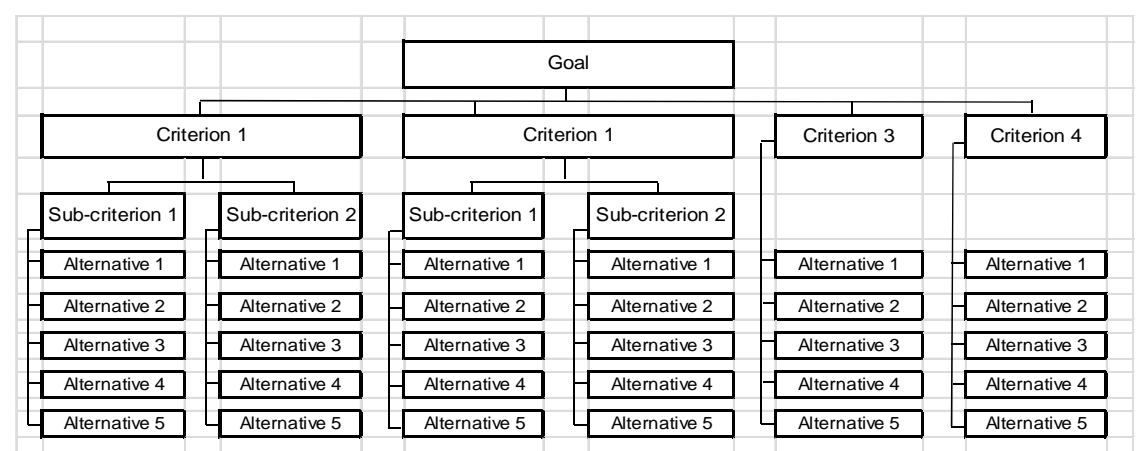

Figure 1: General structure of a decision hierarchy involving four major criteria and five alternatives ${ }^{2}$.

There are four steps to solve a MCDM problem by AHP Method as follows ${ }^{2}$ : Step 1 - Decompose the problem at hand and find out the salient factors and elements (criteria, sub-criteria and alternatives) of the problem. Then construct the linear hierarchy of the problem, see Figure 1. Step 2 - Construct pairwise comparison matrices for all the criteria, sub-criteria (if available), and alternatives. Step 3 Determine the weights of each criteria, sub-criteria (if available) and alternatives from the pairwise comparison matrices obtained is Step 2 by using a suitable weight determination technique. Step 4 Synthesize all the local set of weights computed in Step 3 and obtain a set of overall weights for the alternatives.

\subsection{Goal}

The goal of this paper is to select the best technical service provider to deliver a field development plan (FDP) of the Field X based on the following scope of works has to be completed 
within 24 months. The scope of works includes updating the static model, updates the dynamic model, conducts enhanced oil recovery (EOR) screening, conducts prediction performance for EOR alternatives, develops a development concept, estimates cost, and documents the results into a field development plan (FDP) of the Field X.

\subsection{Define Criteria to select the objective}

After defining the goal, we need to define the criteria. The criteria could be as many we could define, and then we assign a weight to each criterion. For this paper, we select the first top 5 criteria to make exercise. Those five criteria are as the following: Project Deliverability (PD), Technical Capability (TC), Reliability Company (RC), Track Record Performance (TR), Cost (CT), and Technology Transfer (TT)

\subsection{Identify alternatives}

The next step we identify alternatives. The alternatives are the technical service providers worldwide including the regional and local players. Among the list, there are selected five alternatives that could be able to deliver the work scopes. Those alternatives are as follows:

\begin{tabular}{|c|c|l|}
\hline No. & Provider Code & \multicolumn{1}{c|}{ Definition } \\
\hline 1 & Provider 01 & International major technical secvice provider \\
\hline 2 & Provider 02 & Regional technical service provider \\
\hline 3 & Provider 03 & Regional technical service provider \\
\hline 4 & Provider 04 & International major technical service provider \\
\hline 5 & Provider 05 & International technical service provider \\
\hline
\end{tabular}

\subsection{Survey}

The survey was conducted through a questionnaire. There were 15 questionnaires which sent to the high rank technical expertise within the Company. The questionnaire contains five main parts:

Part A - Asking about personal information.

Part B - Regarding the technical service providers; asking to make an overall ranking, and comparisons of performance or priority by rating according to the given scales.

Part C - Asking about the criteria selecting the technical providers. There are two parts here, first part is asking make overall ranking of the criteria, second part is asking to compare the criteria by rating based on its importance using the scales which are given.

Part D - Asking to give a response on the pairwise comparison matrix (PCM) of the alternatives with respect to each criteria. This part we need to make sure that the respondent understand and make that everybody consistent on making their responses. To have good quality responses, we need to call or visit one by one of the respondents to give a clarification to what we really asking about. Please see Appendix A and example

\subsection{Survey results}

There were 15 questionnaires have sent to the selected high rank technical expertise within the Company. There were 11 expertises returned the questionnaires. The demography of the respondents can be seen on Figure 2. The gender indicates that is only one female (9\%), and the rest are male. 


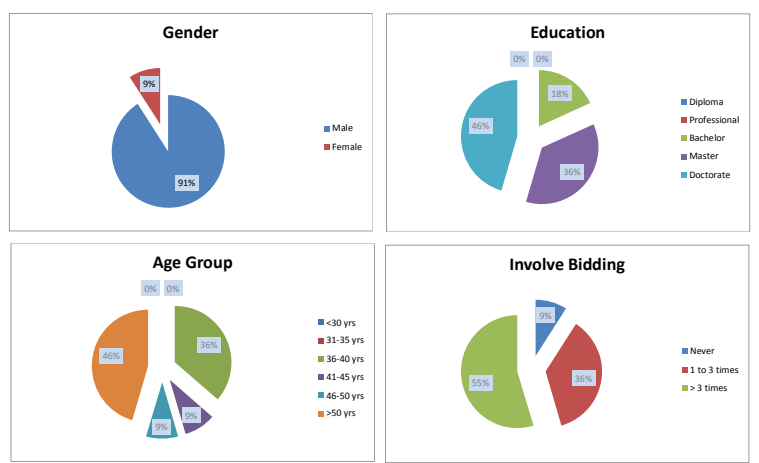

Figure 2: Demography of the respondents.

The education background shows majorities having doctorate background (46\%), followed by master background (36\%). The age group indicates that the respondents are majority from very experience geoscientists (46\%) and follows middle age experience geoscientists (36\%). The age group has correlation with the involvement of the respondent on having bidding experiences. The majority respondents have involve on the technical bidding activities: more than 3 times (55\%), one to three times involvement $(36 \%)$, and only $9 \%$ population has not involve on the bidding process. The results of the questionnaires are then inputted into a spread sheet template.

\section{Solving the technical service provider problem by using AHP}

As mentioned on Section 2.1 above, after defining the goal, criteria and alternatives, then we construct the linear hierarchy of the problem. Figure 6 shows the hierarchy of the technical service provider selection.

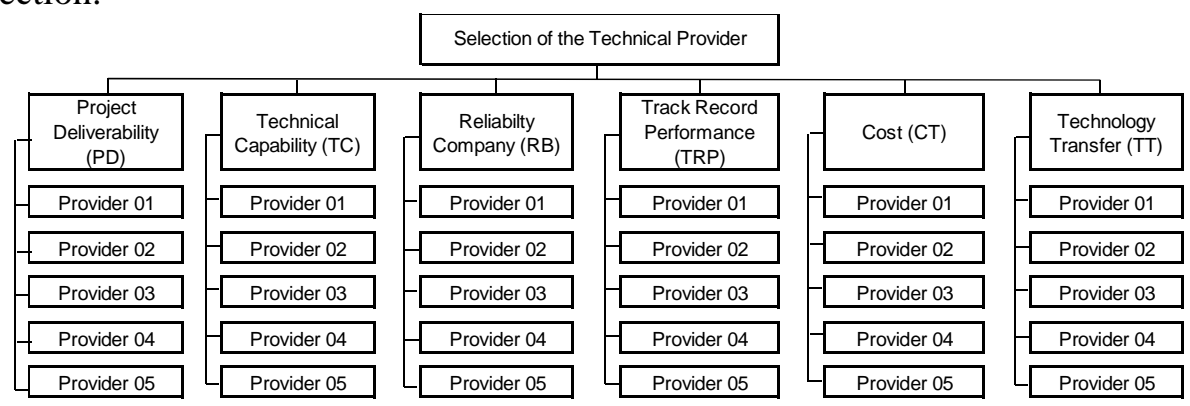

Figure 3: Hierarchy of the technical service provider selection.

The next step is to determine the weights of each criteria. We compute the weights of the criteria by using Saaty's pairwise comparison method. To apply pairwise comparison method, we need to form a pairwise comparison matrix (PCM) for all the criteria. To construct this matrix, we use Saaty's $(1 / 9,9)$ ratio scale. Table 1 shows the interpretation of this scale.

Table 1: Saaty's $(1 / 9,9)$ ratio scale ${ }^{2}$.

\begin{tabular}{|l|c|}
\hline \multicolumn{1}{|c|}{ Verbal judgement of importance } & Numerical rating \\
\hline Equal important & 1 \\
\hline Equal to moderate importanve & 2 \\
\hline Moderate importance & 3 \\
\hline Moderate to strong importance & 4 \\
\hline Strong importance & 5 \\
\hline Strong to very strong importance & 6 \\
\hline Very strong importance & 7 \\
\hline Very strong to extremely strong importance & 8 \\
\hline Extreme importance & 9 \\
\hline
\end{tabular}

The general form of a criteria PCM is as follows: 


\begin{tabular}{|c|c|c|c|c|c|}
\hline & C1 & C2 & C3 &.. & Cn \\
\hline C1 & W1/W1 & W1/W2 & W1/W3 &.. & W1/Wn \\
\hline C2 & W2/W1 & W2/W2 & W2/W3 &.. & W2/Wn \\
\hline C3 & W3/W1 & W3/W2 & W3/W3 & & W3/Wn \\
\hline.$\cdot$ &.. &.$\cdot$ &.. &.$\cdot$ &.. \\
\hline Cn & Wn/W1 & Wn/W2 & Wn/W3 &.. & Wn/Wn \\
\hline
\end{tabular}

Where $\mathrm{W} 1, \mathrm{~W} 2, \mathrm{~W} 3, \ldots, \mathrm{Wn}$ are the numerical weights of the criteria $\mathrm{C} 1, \mathrm{C} 2, \mathrm{C} 3, \ldots, \mathrm{Cn}$ respectively. According to the interpretation of $(1 / 9,9)$ ratio scale, for example on the above table, if criteria $\mathrm{C} 1$ is moderate importance to $\mathrm{C} 2$, then $\mathrm{W} 1 / \mathrm{W} 2=3$. If $\mathrm{C} 1$ is strongly more important over $\mathrm{C} 3$, then $\mathrm{W} 1 / \mathrm{W} 3=5$. By combining the weight of each criteria with respect other criteria using a guideline of the Table 1 Saaty's $(1 / 9,9)$ ratio scale, we could fill the above table for each $\mathrm{Wi} / \mathrm{Wj}$ where $i, j=1,2,3 \ldots . n$. Table 2 provides an example of verbal judgement for one of the respondents.

Table 2: Verbal judgment pertaining to the important of the technical service provider selection criteria.

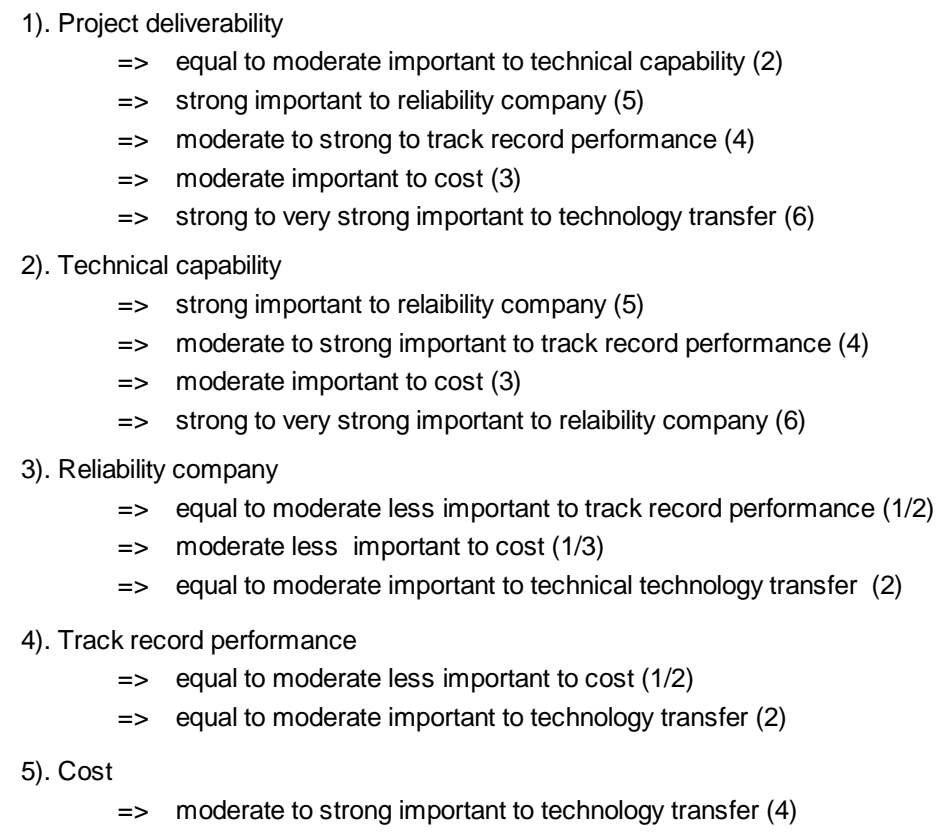

There are three steps to compute of the weight of each criteria using this procedure ${ }^{2}$ : (a) sum the values in each column of the PCM, (b) divide each element in the matrix by its column total. This is referred to as the normalized PCM, (c) compute the average of the elements in each row of the normalize matrix to get the weight of each criteria. Table 3 shows the computation of weights by using row-column normalization procedure from the questionnaire respondent of \#05.

Table 3: Computation of weight for the criteria by using row-column normalization procedure. 


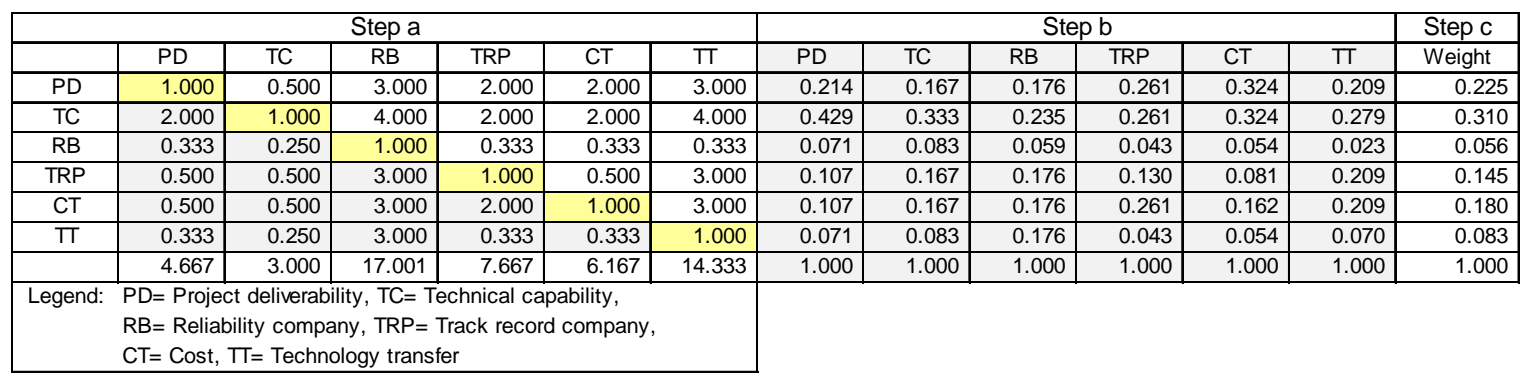

\subsection{Measuring consistency in decision making judgments}

We need to measure the consistency of the above response to make sure that his judgments are consistent. There are several steps to calculate the consistency.

Step a - multiply the first column by the weight of the first criterion. Next multiply the second column by the weight of the second criterion, and so on. Add the elements across the rows. This gives us a weighted sum vector.

Step b - divide each element of the weighted sum vector by the weights of the criteria. First element should be divided by the weight of the first criterion; second element should be divided by the weight of the second criterion, and so on. This division gives us the consistency vector.

Step c - Calculate the average of the elements of the consistency vector, which is called "lamda" and it is denoted by $\lambda$. In this case $\lambda=6.31$.

\begin{tabular}{|c|r|r|}
\hline Cirteria & Step $\mathrm{a}$ & \multicolumn{1}{c|}{ Step b } \\
\hline PD & 1.45 & 6.43 \\
\hline TC & 1.97 & 6.34 \\
\hline RB & 0.34 & 6.18 \\
\hline TRP & 0.92 & 6.33 \\
\hline CT & 1.16 & 6.40 \\
\hline TT & 0.51 & 6.16 \\
\hline
\end{tabular}

Step $\mathrm{d}$ - Calculate the consistency index (CI) by using the following formula:

$$
\begin{aligned}
& \mathrm{CI}=(\lambda-\mathrm{n}) /(\mathrm{n}-1) \\
& \mathrm{CI}=(6.31-6) /(6-1)=0.0615
\end{aligned}
$$

CI provides a measure of departure from consistency. When $\mathrm{CI}=0$ (meaning that $\lambda=\mathrm{n}$ ), the PCM is perfectly consistent (there is no inconsistency in the PCM).

Step e-Calculate the consistency ratio (CR). This is the actual measure of consistency. It is defined as follows:

$\mathrm{CR}=\mathrm{CI} / \mathrm{RI}$, where RI is Random Index. This value is taken from the random indexes for various size of the PCM. For the size of PCM in this case is 6, so the RI is equal to 1.24. Therefore we can calculate $\mathrm{CR}$ which is equal to 0.05 . The $\mathrm{CR}$ is used to see to what extent the elements in the PCM are randomly arranged. If the CR value is less than 0.10 , the amount of inconsistency present in the PCM is acceptable. In the case of our case, it is acceptable since CR is equal to 0.05. For each respondent, we calculate using similar approaches.

The next procedure is to compute the PCM of the alternatives with respect to each criterion. Similar to Table 3, we also compute the weight for the alternatives with respect to each criterion by using row-column normalization procedure. This procedure is similar to the procedure as of the evaluating criteria. All respondents are calculated independently. For this example, we use respondent of \#5. This is similar to the Table 3 above.

Table 4a: Computation of weight for the alternatives with respect to each criterion by using rowcolumn normalization procedure of the respondent \#05. 


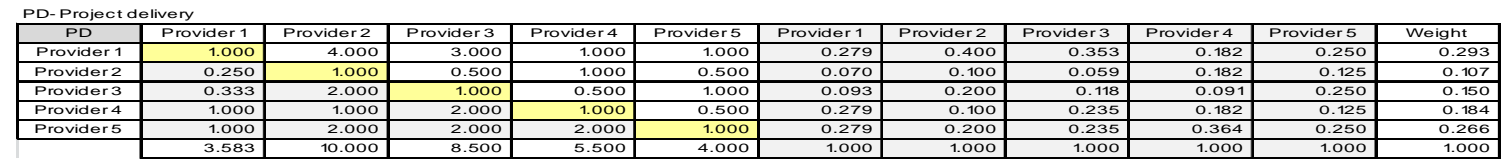

\begin{tabular}{|c|c|c|c|c|c|c|c|c|c|c|c|}
\hline TC & Provider 1 & Provider 2 & Provider 3 & Provider 4 & Provider 5 & Provider 1 & Provider 2 & Provider 3 & Provider 4 & Provider 5 & Weight \\
\hline Provider 1 & 1.000 & 4.000 & 3.000 & 2.000 & 1.000 & 0.324 & 0.308 & 0.400 & 0.308 & 0.324 & 0.333 \\
\hline Provider 2 & 0.250 & 1.000 & 0.500 & 0.500 & 0.250 & 0.081 & 0.077 & 0.067 & 0.077 & 0.081 & 0.077 \\
\hline Provider 3 & 0.333 & 2.000 & 1.000 & 1.000 & 0.333 & 0.108 & 0.154 & 0.133 & 0.154 & 0.108 & 0.131 \\
\hline Provider 4 & 0.500 & 2.000 & 1.000 & 1.000 & 0.500 & 0.162 & 0.154 & 0.133 & 0.154 & 0.162 & 0.153 \\
\hline Provider 5 & 1.000 & 4.000 & 2.000 & 2.000 & 1.000 & 0.324 & 0.308 & 0.267 & 0.308 & 0.324 & 0.306 \\
\hline & 3.083 & 13.000 & 7.500 & 6.500 & 3.083 & 1.000 & 1.000 & 1.000 & 1.000 & 1.000 & 1.000 \\
\hline
\end{tabular}

\begin{tabular}{|c|c|c|c|c|c|c|c|c|c|c|c|}
\hline $\mathrm{RB}$ & Provider 1 & Provider 2 & Provider 3 & $\begin{array}{l}\text { Provider } 4 \\
\end{array}$ & $\begin{array}{l}\text { Provider } 5 \\
\end{array}$ & $\begin{array}{l}\text { Provider } 1 \\
\end{array}$ & Provider 2 & $\begin{array}{l}\text { Provider } 3 \\
\end{array}$ & $\begin{array}{l}\text { Provider } 4 \\
\end{array}$ & $\begin{array}{l}\text { Provider } 5 \\
\end{array}$ & Weight \\
\hline Provider 1 & 1.000 & 3.000 & 3.000 & 1.000 & 2.000 & 0.316 & 0.333 & 0.375 & 0.250 & 0.400 & 0.335 \\
\hline Provider 2 & 0.333 & 1.000 & 1.000 & 0.500 & 0.500 & 0.105 & 0.111 & 0.125 & 0.125 & 0.100 & 0.113 \\
\hline Provider 3 & 0.333 & 1.000 & 1.000 & 0.500 & 0.500 & 0.105 & 0.111 & 0.125 & 0.125 & 0.100 & 0.113 \\
\hline Provider 4 & 1.000 & 2.000 & 2.000 & 1.000 & 1.000 & 0.316 & 0.222 & 0.250 & 0.250 & 0.200 & 0.248 \\
\hline Provider 5 & 0.500 & 2.000 & 1.000 & 1.000 & 1.000 & 0.158 & 0.222 & 0.125 & 0.250 & 0.200 & 0.191 \\
\hline & 3.167 & 9.000 & 8.000 & 4.000 & 5.000 & 1.000 & 1.000 & 1.000 & 1.000 & 1.000 & 1.000 \\
\hline
\end{tabular}

\begin{tabular}{|c|c|c|c|c|c|c|c|c|c|c|c|}
\hline TRP & Provider 1 & Provider 2 & Provider 3 & $\begin{array}{l}\text { Provider } 4 \\
\end{array}$ & $\begin{array}{l}\text { Provider } 5 \\
\end{array}$ & Provider 1 & Provider 2 & $\begin{array}{l}\text { Provider } 3 \\
\end{array}$ & $\begin{array}{l}\text { Provider } 4 \\
\end{array}$ & $\begin{array}{l}\text { Provider } 5 \\
\end{array}$ & Weight \\
\hline Provider 1 & 1.000 & 4.000 & 2.000 & 2.000 & 1.000 & 0.308 & 0.286 & 0.267 & 0.343 & 0.324 & 0.305 \\
\hline Provider 2 & 0.250 & 1.000 & 0.500 & 0.333 & 0.250 & 0.077 & 0.071 & 0.067 & 0.057 & 0.081 & 0.071 \\
\hline Provider 3 & 0.500 & 2.000 & 1.000 & 0.500 & 0.333 & 0.154 & 0.143 & 0.133 & 0.086 & 0.108 & 0.125 \\
\hline Provider 4 & 0.500 & 3.000 & 2.000 & 1.000 & 0.500 & 0.154 & 0.214 & 0.267 & 0.171 & 0.162 & 0.194 \\
\hline Provider 5 & 1.000 & 4.000 & 2.000 & 2.000 & 1.000 & 0.308 & 0.286 & 0.267 & 0.343 & 0.324 & 0.305 \\
\hline & .250 & bo & 7.500 & 5.833 & 3.083 & 1.000 & 1.000 & 1.000 & 1.000 & 1.000 & 1.000 \\
\hline
\end{tabular}

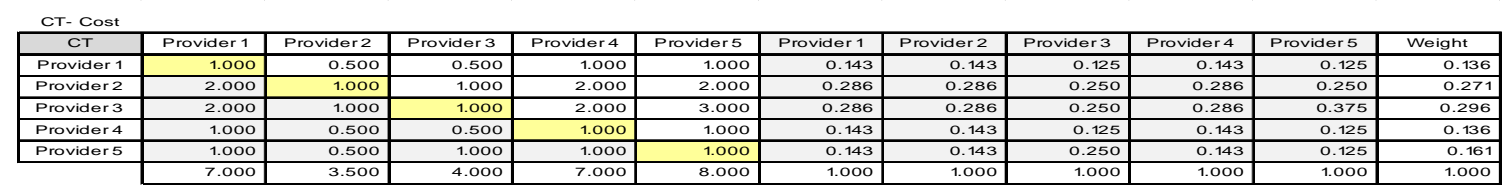

\begin{tabular}{|c|c|c|c|c|c|c|c|c|c|c|c|}
\hline TT & Provider 1 & Provider 2 & Provider 3 & Provider 4 & Provider 5 & Provider 1 & Provider 2 & Provider 3 & Provider 4 & Provider 5 & Weight \\
\hline Provider 1 & 1.000 & 0.333 & 0.333 & 1.000 & 0.500 & 0.100 & 0.100 & 0.087 & 0.143 & 0.077 & 0.101 \\
\hline Provider 2 & 3.000 & 1.000 & 1.000 & 2.000 & 2.000 & 0.300 & 0.300 & 0.261 & 0.286 & 0.308 & 0.291 \\
\hline Provider 3 & 3.000 & 1.000 & 1.000 & 2.000 & 2.000 & 0.300 & 0.300 & 0.261 & 0.286 & 0.308 & 0.291 \\
\hline Provider 4 & 1.000 & 0.500 & 0.500 & 1.000 & 1.000 & 0.100 & 0.150 & 0.130 & 0.143 & 0.154 & 0.135 \\
\hline Provider 5 & 2.000 & 0.500 & 1.000 & 1.000 & 1.000 & 0.200 & 0.150 & 0.261 & 0.143 & 0.154 & 0.182 \\
\hline & 10.000 & 3.333 & 3.833 & 7.000 & 6.500 & 1.000 & 1.000 & 1.000 & 1.000 & 1.000 & 1.000 \\
\hline
\end{tabular}

Table 4b: Synthesis results to obtain the global (overall) weight for the respondent of \#05.

\begin{tabular}{|l|r|r|r|r|r|r|r|}
\hline & \multicolumn{1}{|c|}{ PD } & \multicolumn{1}{c|}{ TC } & \multicolumn{1}{c|}{ RB } & \multicolumn{1}{c|}{ TRP } & \multicolumn{1}{c|}{ CT } & \multicolumn{1}{c|}{ TT } & $\begin{array}{c}\text { Overall } \\
\text { Weights }\end{array}$ \\
\cline { 2 - 8 } & 0.225 & 0.310 & 0.056 & 0.145 & 0.180 & 0.083 & \\
\hline Provider1 & 0.293 & 0.333 & 0.335 & 0.305 & 0.136 & 0.101 & 0.265 \\
\hline Provider2 & 0.107 & 0.077 & 0.113 & 0.071 & 0.271 & 0.291 & 0.138 \\
\hline Provider 3 & 0.150 & 0.131 & 0.113 & 0.125 & 0.296 & 0.291 & 0.177 \\
\hline Provider 4 & 0.184 & 0.153 & 0.248 & 0.194 & 0.136 & 0.135 & 0.167 \\
\hline Provider 5 & 0.266 & 0.306 & 0.191 & 0.305 & 0.161 & 0.182 & 0.254 \\
\hline & 1.000 & 1.000 & 1.000 & 1.000 & 1.000 & 1.000 & 1.000 \\
\hline
\end{tabular}

Table 4a shows PCM and a computation of weight for the alternatives with respect to each criterion by using row-column normalization procedure for the respondent \#05. The calculation of Table $4 \mathrm{a}$ is similar to the calculation of Table 3 . Table $4 \mathrm{~b}$ shows synthesis results to obtain the global (overall) weight for the respondent of \#05. The overall weights of each provider are calculated by using the following formula:

$$
\mathrm{W}_{j}=\sum_{i=1}^{n} p_{i} q_{i j}
$$

Where $p_{i}, i=1,2,3 \ldots, \mathrm{n}$ are the weights of the criteria and $q_{i j}, j=1,2,3 \ldots, \mathrm{m}$ are the weight of the alternatives ' $j$ ' with respect to criterion ' $i$ '. By applying this formula we can calculate the global (overall) weight of each alternative. From Table $4 \mathrm{~b}$ has found that the overall weight for Provider 1, Provider 2, Provider 3, Provider 4, and Provider 5 are 0.265, 0.138, 0.177, 0.167, and 0.254 respectively. Therefore the Provider 5 has the highest overall weight among the others. This calculation is based on one respondent. We have to calculate with similar method other respondents.

After completing calculating for each respondent, then develop an average value for each element, both the criteria and the alternatives. The average method that we use is a geometric mean 
(geometric average). The geometric mean of a data set $\left\{a_{1}, a_{2}, \ldots, a_{n}\right\}$ is given by the following formula:

$$
\left(\prod_{i=1}^{n} a_{i}\right)^{1 / n}=\sqrt[n]{a_{1} a_{2} \cdots a_{n}}
$$

Where $\mathbf{a}$ is value for each element for each respondent and $\mathrm{n}$ is the total number of respondents.

Table 5: Geometric mean of PCM of each criterion.

\begin{tabular}{|c|c|c|c|c|c|c|c|c|c|c|c|c|c|}
\hline & $\mathrm{PD}$ & $\mathrm{TC}$ & $\mathrm{RB}$ & TRP & CT & $\pi T$ & $\mathrm{PD}$ & TC & $\mathrm{RB}$ & TRP & CT & $\pi$ & Weight \\
\hline PD & 1.000 & 0.906 & 3.257 & 1.739 & 1.426 & 3.120 & 0.250 & 0.249 & 0.224 & 0.273 & 0.254 & 0.213 & 0.244 \\
\hline TC & 1.104 & 1.000 & 3.394 & 1.739 & 1.641 & 4.000 & 0.275 & 0.275 & 0.233 & 0.273 & 0.293 & 0.273 & 0.270 \\
\hline $\mathrm{RB}$ & 0.307 & 0.295 & 1.000 & 0.403 & 0.307 & 0.855 & 0.077 & 0.081 & 0.069 & 0.063 & 0.055 & 0.058 & 0.067 \\
\hline TRP & 0.575 & 0.575 & 2.479 & 1.000 & 0.906 & 2.627 & 0.144 & 0.158 & 0.170 & 0.157 & 0.162 & 0.179 & 0.162 \\
\hline CT & 0.701 & 0.610 & 3.257 & 1.104 & 1.000 & 3.045 & 0.175 & 0.168 & 0.224 & 0.173 & 0.178 & 0.208 & 0.188 \\
\hline $\mathrm{TT}$ & 0.320 & 0.250 & 1.170 & 0.381 & 0.328 & 1.000 & 0.080 & 0.069 & 0.080 & 0.060 & 0.059 & 0.068 & 0.069 \\
\hline Sum & 4.008 & 3.635 & 14.557 & 6.365 & 5.608 & 14.648 & 1.000 & 1.000 & 1.000 & 1.000 & 1.000 & 1.000 & 1.000 \\
\hline Legend: & $\begin{array}{l}\mathrm{D}=\text { Projec } \\
\mathrm{B}=\text { Reliabi } \\
\mathrm{T}=\text { Cost }, \mathrm{T}\end{array}$ & $\begin{array}{l}\text { liverabilit } \\
\text { company } \\
\text { Technolo }\end{array}$ & $\begin{array}{l}\mathrm{C}=\mathrm{Tech} \\
\mathrm{PP}=\text { Trac } \\
\text { transfer }\end{array}$ & & & & & & & & & & \\
\hline
\end{tabular}

Table 5 shows summarizing the results PCM for each criterion using the geometric mean as mentioned above. Technical Capability and Project Deliverability criteria have the highest and second highest overall weight, while Reliable Company criterion has the lowest overall weight. The next step is calculating the alternatives with respect to each criterion. Similar approach to the Table 5 above, we calculate each element using the geometric mean also. Table 6a shows the results of the alternatives with respect to each criteria. With respect to Project Delivery, Provider 5 and Provider 4 have the first and the second highest weight value; those are 0.329 and 0.291 respectively. Similarly with respect to Technical Provider, these both providers have the first and second highest weight value; those 0.359 and 0.259 respectively.

Table 6a: PCM of the alternatives with respect to the criteria. 


\begin{tabular}{|c|c|c|c|c|c|c|c|c|c|c|c|}
\hline PD & Provider 1 & \begin{tabular}{|l} 
Provider 2 \\
\end{tabular} & Provider 3 & Provider 4 & \begin{tabular}{|l|} 
Provider 5 \\
\end{tabular} & Provider 1 & \begin{tabular}{|l} 
Provider 2 \\
\end{tabular} & Provider 3 & Provider 4 & Provider 5 & Weight \\
\hline Provider 1 & 1.000 & 3.617 & 2.521 & 1.811 & 0.743 & 0.280 & 0.312 & 0.337 & 0.280 & 0.245 & 0.291 \\
\hline Provider 2 & 0.276 & 1.000 & 0.610 & 0.505 & 0.300 & 0.077 & 0.086 & 0.081 & 0.078 & 0.099 & 0.084 \\
\hline Provider 3 & 0.397 & 1.641 & 1.000 & 0.906 & 0.543 & 0.111 & 0.142 & 0.134 & 0.140 & 0.179 & 0.141 \\
\hline $\begin{array}{l}\text { Provider } 4 \\
\end{array}$ & 0.552 & 1.982 & 1.104 & 1.000 & 0.445 & 0.155 & 0.171 & 0.148 & 0.155 & 0.147 & 0.155 \\
\hline \multirow[t]{2}{*}{ Provider 5} & 1.346 & 3.337 & 2.246 & 2.246 & 1.000 & 0.377 & 0.288 & 0.300 & 0.347 & 0.330 & 0.329 \\
\hline & 3.571 & 11.577 & 7.481 & 6.467 & 3.031 & 1.000 & 1.000 & 1.000 & 1.000 & 1.000 & 1.000 \\
\hline
\end{tabular}

\begin{tabular}{|c|c|c|c|c|c|c|c|c|c|c|c|}
\hline TC & \begin{tabular}{|l|} 
Provider 1 \\
\end{tabular} & \begin{tabular}{|l|} 
Provider 2 \\
\end{tabular} & Provider 3 & Provider 4 & \begin{tabular}{|l|} 
Provider 5 \\
\end{tabular} & Provider 1 & \begin{tabular}{|l|} 
Provider 2 \\
\end{tabular} & Provider 3 & Provider 4 & Provider 5 & Weight \\
\hline Provider 1 & 1.000 & 2.784 & 2.380 & 1.486 & 0.635 & 0.248 & 0.260 & 0.316 & 0.234 & 0.235 & 0.259 \\
\hline Provider 2 & 0.359 & 1.000 & 0.673 & 0.575 & 0.271 & 0.089 & o.094 & 0.089 & 0.091 & 0.100 & 0.093 \\
\hline Provider 3 & 0.420 & 1.486 & 1.000 & 0.906 & 0.381 & 0.104 & 0.139 & 0.133 & 0.143 & 0.141 & 0.132 \\
\hline Provider 4 & 0.673 & 1.739 & 1.104 & 1.000 & 0.420 & 0.167 & 0.163 & 0.147 & 0.158 & 0.155 & 0.158 \\
\hline \multirow[t]{2}{*}{ Provider 5} & 1.575 & 3.684 & 2.380 & 2.380 & 1.000 & 0.391 & 0.345 & 0.316 & 0.375 & 0.369 & 0.359 \\
\hline & 4.027 & 10.693 & 7.536 & 6.346 & 2.707 & 1.000 & 1.000 & 1.000 & 1.000 & 1.000 & 1.000 \\
\hline
\end{tabular}

\begin{tabular}{|c|c|c|c|c|c|c|c|c|c|c|c|}
\hline RB & \begin{tabular}{|l|} 
Provider 1 \\
\end{tabular} & \begin{tabular}{|l|} 
Provider2 \\
\end{tabular} & \begin{tabular}{|l|} 
Provider 3 \\
\end{tabular} & \begin{tabular}{|l|} 
Provider 4 \\
\end{tabular} & \begin{tabular}{|l|} 
Provider 5 \\
\end{tabular} & \begin{tabular}{|l|} 
Provider 1 \\
\end{tabular} & \begin{tabular}{|l|} 
Provider 2 \\
\end{tabular} & \begin{tabular}{|l|l|} 
Provider 3 \\
\end{tabular} & \begin{tabular}{|l|} 
Provider 4 \\
\end{tabular} & \begin{tabular}{|l|} 
Provider 5 \\
\end{tabular} & Weight \\
\hline Provider 1 & 1.000 & 2.950 & 2.784 & 1.219 & 1.739 & 0.323 & 0.336 & 0.323 & 0.300 & 0.346 & 0.326 \\
\hline Provider 2 & 0.339 & 1.000 & 0.906 & 0.552 & 0.521 & 0.110 & 0.114 & 0.105 & 0.136 & 0.104 & 0.114 \\
\hline Provider 3 & 0.359 & 1.104 & 1.000 & 0.472 & 0.552 & 0.116 & 0.126 & 0.116 & 0.116 & 0.110 & 0.117 \\
\hline Provider 4 & $\begin{array}{ll}0.820 \\
\end{array}$ & 1.811 & $\begin{array}{ll}2.119 \\
\end{array}$ & 1.000 & 1.219 & 0.265 & 0.206 & 0.246 & 0.246 & 0.242 & 0.241 \\
\hline \multirow[t]{2}{*}{ Provider 5} & 0.575 & 1.920 & 1.811 & 0.820 & 1.000 & 0.186 & 0.219 & 0.210 & 0.202 & 0.199 & 0.203 \\
\hline & 3.094 & 8.785 & 8.620 & 4.063 & 5.030 & 1.000 & 1.000 & 1.000 & 1.000 & 1.000 & 1.000 \\
\hline
\end{tabular}

\begin{tabular}{|c|c|c|c|c|c|c|c|c|c|c|c|}
\hline TRP & Provider 1 & Provider 2 & Provider 3 & $\begin{array}{l}\text { Provider } 4 \\
\end{array}$ & Provider 5 & Provider 1 & \begin{tabular}{|l|} 
Provider 2 \\
\end{tabular} & Provider 3 & \begin{tabular}{|l|} 
Provider 4 \\
\end{tabular} & \begin{tabular}{|l|} 
Provider 5 \\
\end{tabular} & Weight \\
\hline $\begin{array}{l}\text { Provider } 1 \\
\end{array}$ & 1.000 & 3.927 & 2.119 & 1.811 & 1.104 & 0.314 & 0.312 & 0.312 & 0.298 & 0.325 & 0.312 \\
\hline Provider 2 & 0.255 & 1.000 & 0.465 & 0.445 & 0.305 & 0.080 & 0.079 & 0.068 & 0.073 & 0.090 & 0.078 \\
\hline Provider 3 & 0.472 & 2.151 & 1.000 & 0.820 & 0.492 & 0.148 & 0.171 & 0.147 & 0.135 & 0.145 & 0.149 \\
\hline Provider 4 & 0.552 & 2.246 & 1.219 & 1.000 & 0.500 & 0.173 & 0.178 & 0.179 & 0.165 & 0.147 & 0.168 \\
\hline \multirow[t]{2}{*}{ Provider 5} & 0.906 & 3.281 & 2.000 & 2.000 & 1.000 & 0.284 & 0.260 & 0.294 & 0.329 & 0.294 & 0.292 \\
\hline & 3.184 & 12.605 & 6.803 & 6.077 & 3.401 & 1.000 & 1.000 & 1.000 & 1.000 & 1.000 & 1.000 \\
\hline
\end{tabular}

\begin{tabular}{|c|c|c|c|c|c|c|c|c|c|c|c|}
\hline CT & Provider 1 & Provider 2 & Provider 3 & Provider 4 & Provider 5 & Provider 1 & \begin{tabular}{|l|} 
Provider 2 \\
\end{tabular} & Provider 3 & Provider 4 & $\begin{array}{l}\text { Provider } 5 \\
\end{array}$ & Weight \\
\hline Provider 1 & 1.000 & 0.743 & 0.701 & 1.104 & 1.104 & 0.179 & 0.161 & 0.166 & 0.201 & 0.202 & 0.182 \\
\hline Provider 2 & 1.346 & 1.000 & 0.906 & 1.104 & 1.170 & 0.241 & 0.217 & 0.214 & 0.201 & 0.214 & 0.217 \\
\hline Provider 3 & 1.426 & 1.104 & 1.000 & 1.170 & 1.292 & 0.255 & 0.240 & 0.236 & 0.213 & 0.236 & 0.236 \\
\hline Provider 4 & 0.906 & 0.906 & 0.855 & 1.000 & 0.906 & 0.162 & 0.197 & 0.202 & 0.182 & 0.166 & 0.182 \\
\hline \multirow[t]{2}{*}{\begin{tabular}{|l|} 
Provider 5 \\
\end{tabular}} & 0.906 & 0.855 & 0.774 & 1.104 & 1.000 & 0.162 & 0.186 & 0.183 & 0.201 & 0.183 & 0.183 \\
\hline & 5.584 & 4.608 & 4.236 & 5.482 & 5.471 & 1.000 & 1.000 & 1.000 & 1.000 & 1.000 & 1.000 \\
\hline
\end{tabular}

\begin{tabular}{|c|c|c|c|c|c|c|c|c|c|c|c|}
\hline$\pi T$ & Provider 1 & \begin{tabular}{|l|} 
Provider 2 \\
\end{tabular} & Provider 3 & Provider 4 & \begin{tabular}{|l|} 
Provider 5 \\
\end{tabular} & Provider 1 & \begin{tabular}{|l|} 
Provider 2 \\
\end{tabular} & Provider 3 & $\begin{array}{l}\text { Provider } 4 \\
\end{array}$ & \begin{tabular}{|l|} 
Provider 5 \\
\end{tabular} & Weight \\
\hline Provider 1 & 1.000 & 0.369 & 0.339 & 1.104 & 0.543 & 0.106 & 0.100 & 0.075 & 0.133 & 0.112 & 0.105 \\
\hline $\begin{array}{l}\text { Provider } 2 \\
\end{array}$ & 2.712 & 1.000 & 0.906 & 2.119 & 1.346 & 0.288 & 0.271 & 0.200 & 0.256 & 0.277 & 0.258 \\
\hline Provider 3 & 2.950 & 1.104 & 1.000 & 2.208 & 1.426 & 0.313 & 0.299 & 0.220 & 0.267 & 0.294 & 0.279 \\
\hline Provider 4 & 0.906 & 0.472 & 0.453 & 1.000 & 0.543 & 0.096 & 0.128 & 0.100 & 0.121 & 0.112 & 0.111 \\
\hline \multirow[t]{2}{*}{ Provider 5} & 1.842 & 0.743 & 1.842 & 1.842 & 1.000 & 0.196 & 0.201 & 0.406 & 0.223 & 0.206 & 0.246 \\
\hline & 9.411 & 3.688 & 4.540 & 8.274 & 4.858 & 1.000 & 1.000 & 1.000 & 1.000 & 1.000 & 1.000 \\
\hline
\end{tabular}

Table $6 \mathrm{~b}$ shows the summary of synthesis results in order to obtain the overall (global) weights. The approach to get the overall weight is the same as to generating the Table $4 \mathrm{~b}$ above, that is using the following equation: $\mathrm{W}_{j}=\sum_{i=1}^{n} p_{i} q_{i j}$

This indicates that Provider 5 and Provider 1 have the highest and the second highest of the overall weight; those are 0.2895 and 0.2546 respectively, while the Provider 2 has the lowest overall weight; that is 0.1246 .

Table 6b: Synthesis results to obtain the global weight.

\begin{tabular}{|c|c|c|c|c|c|c|r|}
\hline & PD & TC & RB & TRP & CT & T & \multirow{2}{*}{$\begin{array}{c}\text { Overall } \\
\text { Weights }\end{array}$} \\
\cline { 2 - 6 } & 0.244 & 0.270 & 0.067 & 0.162 & 0.188 & 0.069 & \multicolumn{1}{|c|}{0.2546} \\
\hline Provider 1 & 0.291 & 0.259 & 0.326 & 0.312 & 0.182 & 0.105 & 0.1246 \\
\hline Provider 2 & 0.084 & 0.093 & 0.114 & 0.078 & 0.217 & 0.258 & 0.1656 \\
\hline Provider 3 & 0.141 & 0.132 & 0.117 & 0.149 & 0.236 & 0.279 & 0.1656 \\
\hline Provider 4 & 0.155 & 0.158 & 0.241 & 0.168 & 0.182 & 0.111 & 0.1657 \\
\hline Provider 5 & 0.329 & 0.359 & 0.203 & 0.292 & 0.183 & 0.246 & 0.2895 \\
\hline Sum & 1.000 & 1.000 & 1.000 & 1.000 & 1.000 & 1.000 & 1.000 \\
\hline
\end{tabular}

\section{Discussion and Analysis}

We have been discussing using the Analytic Hierarchy Process (AHP) to select the best candidate for the technical service provider to conduct the comprehensive study of the Field $\mathrm{X}$ to deliver the Field Development Plan (FDP) document. With this AHP method we could identify overall weight criteria. Figure 4 shows the results from the comprehensive processes of the AHP method of the selected criteria. 
The Technology Capability and the Project Deliverability criteria show the highest overall weight; those are 0.270 and 0.244 respectively, while Reliability Company and Technology Transfer have similar lowest number of the overall weight; those are 0.067 and 0.069 respectively. The Cost criterion is the third highest, and the Track Record Performance criterion is the fourth highest; those are 0.188 and 0.162 respectively.

The Technology Capability criterion is consistent with the reality of the business activities. This criterion will determine the quality of the product and will drive the accuracy and level of comprehensiveness of the technical assessment. This criterion will assess the uncertainties of the business and mitigate them to reduce the risk. On the other hand, the Project Deliverability criterion is also reflecting the reality of the business. This criterion drives the critical issue to the project timeline of project deliverability.

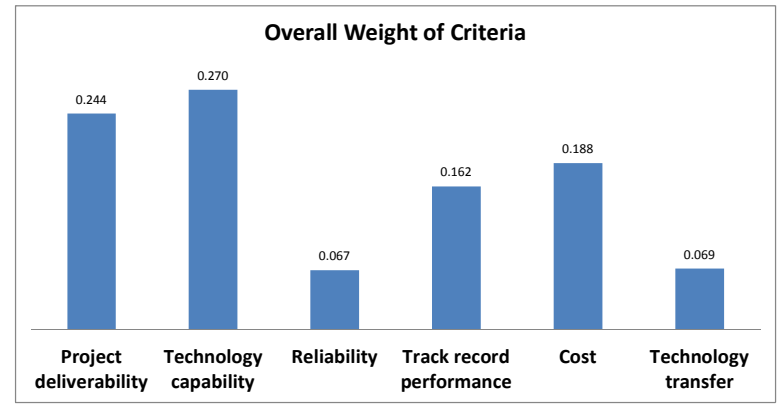

Figure 4: Overall weight of the criteria.

Figure 5 shows the PCM of the alternatives with respect to each criterion. Provider 5 and Provider 1 for both technical capability and project delivery have the highest scores. These two criteria are essentially determining the higher global (overall) weight.

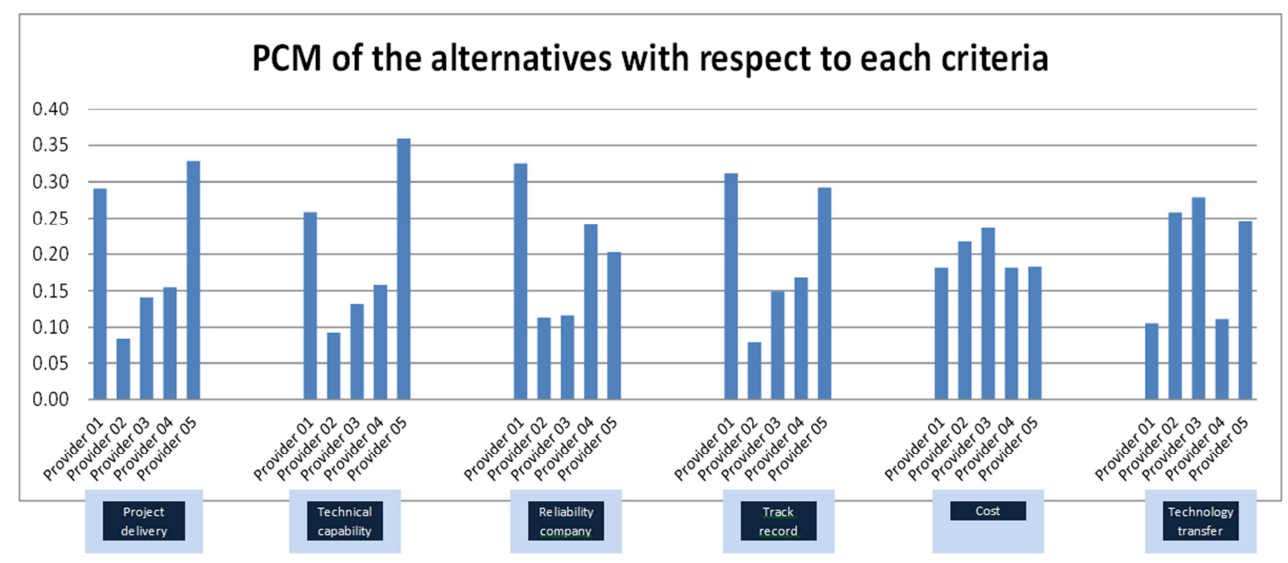

Figure 5: PCM of the alternatives with respect to each criterion.

Finally, Figure 6 shows the overall weight of the providers. The Provider 5 and Provider 1 have the first and second highest overall weight, 0.2895 and 0.2546 respectively. This means that Provider 1 is selected to be the provider to conduct the study to develop field development (FDP) of Field X. The key why Provider 5 has the highest score is that she has the highest technology capability where it is the main criterion which has the highest overall weight. Provider 2 has the lowest overall weight; that is 0.1246. 


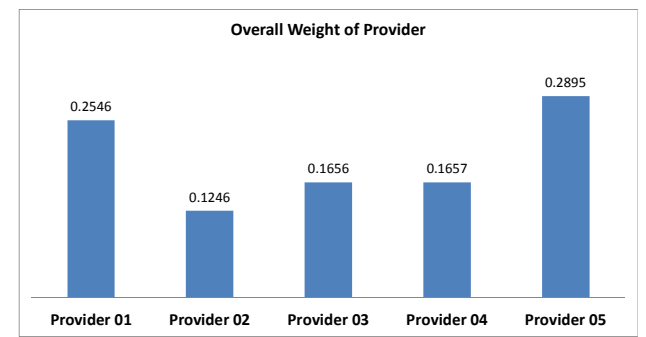

Figure 6: Overall weight of the providers.

Why the Provider 2 has the lowest overall weight? If we see Figure 6 above, Provider 02 has the lowest overall weight in three most important criteria, Technical Capability, Project Deliverability, and Track record performance. Figure 7 shows the comparison overall weight performances between Provider 2, Provider 5 and average overall providers.

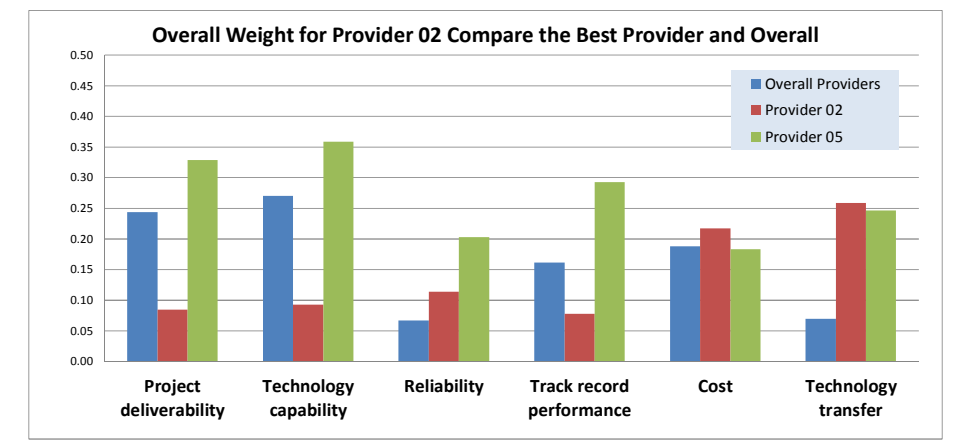

Figure 7: Overall weight for Provider 02 compare to the best provider and to overall average provider.

\section{Conclusion and Recommendation}

1. Technical capability is the most important criterion $(0.270)$, followed by Project Deliverability $(0.244)$ in selecting technical consultant in oil and gas industry.

2. Provider 5 has the highest global weight which is 0.290 followed by Provider 1 which is 0.255 both providers are the international player which already establish in oil and gas industry.

3. Provider 2 is the lowest in term of global weight, which is 0.125 . This is regional base technical consultant company. She needs to improve in Technical Capability criterion and Project Deliverability criterion to compete with international player globally.

4. We need to develop sub-criteria in service provider evaluation, especially for Technical Capability to represent more details of each discipline to access the technical competency in geology \& geophysics, reservoir, production, drilling, completion and facilities, to get the best technical consultant in order to maximize the Company asset. We also need to conduct the survey to be more heterogonous population and improve the percentage of respondent response to see the deeper and better representative results.

\section{Acknowledgement}

The authors would like to thank to all expertise who have provided the inputs and feedback developing this project. The author would like to thank to Br. Masripan Salleh for having a discussion on selecting the topic.

\section{REFERENCE}

1. BP Energy outlook: http://www.bp.com/sectiongenericarticle, 2010.

2. Islam, Rafikul: Advanced Management Science (MGT 7311), Graduate School of Management, IIUM 2011.

3. Riyadi, Slamet: Matured Fields: How to Make PSCs Investing in an EOR Development, DBA, IIUM, 2010.

4. Anderson, David R, Dennis J. Sweeney, Thomas A. Williams: An Introduction to Management Science, South-Western, 2011. 